\title{
ELECTRIC SHIP POWER SYSTEM INTEGRATION ANALYSES THROUGH MODELING AND SIMULATION
}

\author{
By: \\ A. Ouroua \\ L.N. Domaschk \\ J.H. Beno
}

IEEE Electric Ship Technologies Symposium, Philadelphia, Pennsylvania, U.S.A., July 25-27, 2005.

Submitted to: IEEE Electric Ship Technologies Symposium, July 25-27, 2005, Philadelphia, PA.

PN 299

Center for Electromechanics

The University of Texas at Austin

PRC, Mail Code R7000

Austin, TX 78712

(512) 471-4496

$05 / 31 / 2005$ 


\title{
Electric Ship Power System Integration Analyses Through Modeling and Simulation
}

\author{
A. Ouroua, L. Domaschk, and J. H. Beno
}

\begin{abstract}
The Center for Electromechanics (CEM) at the University of Texas is engaged in the development of a comprehensive power system model in order to address several challenging issues facing the development of a viable and effective integrated power system architecture for future naval platforms. The power system under consideration reflects the notional DD power system architecture and is developed in the Matlab/Simulink environment. System components such as motors and generators are modeled using parameters based on actual machine design and analysis work performed at CEM. Simulation results of models including permanent-magnet propulsion motors and generators with simple reconfiguration scenarios simulating loss and recovery of power to propulsion and vital loads are presented.
\end{abstract}

Index Terms-Electric ship, modeling, power system integration, reconfiguration.

\section{INTRODUCTION}

The introduction of electric propulsion into naval platforms resulted in a significant increase of the electric power level from few mega-watts found on present-day ships, and used mainly for ship services and other loads requiring modest electric power consumption, to several tens of mega-watts for future all-electric ships. The generation, distribution, and utilization of such a large power level in a small environment are proving to be extremely challenging. The required size reduction of the propulsion power train, i.e., prime movers, generators, transformers, motor drives, and propulsion motors, precludes the use of existing equipment and demands that new technologies be developed and implemented for use on a naval platform taking into consideration all the constraints it encompasses. The additional requirement imposed by new systems that use intermittent high pulse power has made an effective integration of the overall power system a crucial factor for a successful all-electric platform. The control and management of power on board electric ships are therefore key issues that need to be addressed in order to determine the optimum power system architecture and the most effective control and operating modes.

This work was supported by a grant from the Office of Naval Research, US Navy.

A. Ouroua (e-mail: a.ouroua@mail.utexas.edu), L. Domaschk (email: ldomaschk@mail.utexas.edu), and J.H. Beno (email: j.beno@mail.utexas.edu) are with The University of Texas at Austin, Center for Electromechanics, 1 University Station R7000, Austin, TX 78712 USA.
The Center for Electromechanics at the University of Texas has been conducting research on electric ship power train technologies under the Electric Ship Research and Development Consortium (ESRDC). Our initial research was directed towards understanding issues associated with the inclusion of electric propulsion, and identifying critical, high pay-off technology needs that would enable a major improvement of the propulsion power train size and efficiency. Results of this analysis which included the design of a $20 \mathrm{MW}$ propulsion power train can be found in [1]-[2]. Issues associated with pulse power needs and their effect on the power system as well as those related to energy storage and power management have also been studied. The results are discussed in [3]-[5].

The importance to study the power system as a whole, in contrast to looking at individual components, has prompted us to concentrate our present efforts on developing a model of the electric ship power system. The model allows us to simulate realistic operating scenarios, thereby providing an assessment of the power system performance under prescribed conditions. As indicated earlier, the introduction of new technologies for some components, such as generators and propulsion motors, is necessary in order to achieve the required level of power density. The power system model will allow us to assess the performance of these new technologies and their effects, if any, on the power system. In addition, the model can be an environment in which reconfiguration scenarios are analyzed, and energy storage and power quality issues readily addressed. Finally, since several auxiliary loads will require specific power supplies, the model is an appropriate platform to study their interaction with the overall power system.

A description of the electric ship power system under consideration is given in section II. Section III is a description of the model used along with a discussion on the computing environment chosen. Analyses examples are presented in section IV and a conclusion summarizing our results is given in section $\mathrm{V}$.

\section{THE ELECTRIC SHIP POWER SYSTEM}

Apart from the inclusion of electric propulsion, the electric ship power system architecture envisaged for future electric ship differs from present-day architectures in that it must support new systems that require pulse power levels that are two to three orders of magnitude larger than the total power installed on board the electric ship. This is a stringent requirement that will probably affect the design of the electric 
ship power system architecture, its control, and mode of operations. The power system architecture under consideration is based on the notional DD architecture which attempts to mirror the power system of the DDX ships. Since information on DDX is very limited, the notional DD data was derived from knowledge of present-day navy practices, and information pertinent to the development of specific equipments such as permanent-magnet and high-temperature superconducting propulsion motors. On-going discussions in the electric ship development community related to the type of distribution (AC or DC), and the appropriate voltage levels, among other considerations, are also a source of data for the notional DD architecture. Most of the notional DD data used in our work was provided by Syntek [6] to ESRDC members.

Prime movers consist of four gas turbine-generator sets. Two (main) $36 \mathrm{MW}$ and two (auxiliary) $4 \mathrm{MW}$ gen-sets generate a total of $80 \mathrm{MW}$ of electric power. The smaller gensets and service loads considered here are similar to those used in current ships. A schematic of the overall power system is shown in Fig. 1. For simplicity, the smaller generators are shown connected to service loads numbered from one to eight and representing only one of five zones. However, since electric power is integrated, service loads as well as propulsion loads, and auxiliary loads, can be supplied through a combination of the four gen-sets.

The propulsion power train consists of a transformer, a rectifier, an inverter, and a propulsion motor. The auxiliary power supplies are for EM guns and other pulse power systems.

\section{THE MODEL}

A model of the electric ship power system described in the previous section was built in the Matlab/Simulink graphical programming environment. Our initial choice of this computing platform was based on the availability, familiarity, and experience with the software that is routinely used at the Center for Electromechanics for this type of simulations. Issues regarding execution time, ease of modeling, and portability were raised by several consortium members and other computing environments needed to be considered. To answers these concerns, we developed an electric ship power system model in the Acsl [7] computing environment. The Acsl model was built as close as possible to the Simulink model for comparison purposes. While both computing platforms have advantages and disadvantages, we found no significant differences between the two computing environments, in terms of execution time, when the accelerator module and native blocks are used with Simulink. We are presently looking at the virtual test bed (VTB) [8] computing environment. The results will be reported when the model is completed and tested. Finally, simulation of complicated, real time scenarios, involving all components of the electric ship power system may require extensive computing resources that are beyond the capabilities of desk top platforms. To that effect, we are considering using the supercomputing resources that are available to us at the University of Texas.
Using the Matlab/Simulink platform, all components shown in the line diagram on Fig. 1. were modeled, except for the gas turbines which have not been included yet. In our initial modeling effort pre-programmed components from the commercial toolbox SimPowerSystems were used but were found to be inadequate in terms of parameter control and execution time. We re-built the model using native Simulink blocks and programmed our own blocks using S-functions whenever necessary. This allows a more efficient modeling, a better control over model parameters, and helps in preventing the occurrence of algebraic loops which are often the cause behind computation slow down during execution.

A top-level representation of the present Simulink model is shown in Fig. 2. Icons are used to describe the different components in the model for clarity.

The main generators are modeled as actively-cooled permanent-magnet generators running at $3600 \mathrm{rpm}$. The choice of speed is to allow a direct coupling to the MT30 gas turbines which also run at $3600 \mathrm{rpm}$. The auxiliary generators are also modeled as actively-cooled permanent-magnet machines running at $3600 \mathrm{rpm}$ despite the fact that the auxiliary gas turbines under consideration, mainly the MT5 and LM500 turbines operate at much higher speeds thereby requiring gear boxes; an unlikely topology in future configurations. The gas turbine-generator set is a major component of the electric ship power system that can, and should, be optimized in order to reduce the overall size as discussed in the introduction. A research project that addresses this issue has been initiated at CEM. The investigation is looking into the feasibility of using directly-coupled highspeed gas turbine-generator sets. Such a topology results in the elimination of coupling gears and size reduction, allowing the gen-set to be installed on upper-decks, thereby freeing valuable space otherwise occupied by air ducts. The optimization of the prime power gen-sets is perhaps a crucial factor for a successful integrated power system on board future ships.

The main distribution frequency and voltages used in the model are, respectively, $60 \mathrm{~Hz}$ and $13.8 \mathrm{kV}$. The three-phase propulsion transformer, $13.8 \mathrm{kV} / 4.16 \mathrm{kV}$, is connected to an uncontrolled rectifier which supplies a PWM inverter that drives the propulsion motor. The parameters of the radial-flux permanent magnet synchronous motor are obtained through design and analyses efforts performed at CEM as is also the case for the generators. The $36.5 \mathrm{MW}, 150 \mathrm{rpm}$ motor model is made to reflect, as closely as possible, the motor being developed for ONR by DRS technologies.

Service zones include both AC and DC loads. An expanded model of a typical service zone is shown in Fig. 3. It includes two load center transformers, two AC buses, two DC buses, six AC loads, two DC loads, a ship service transformer, two thyristors, an inverter, and a converter. 


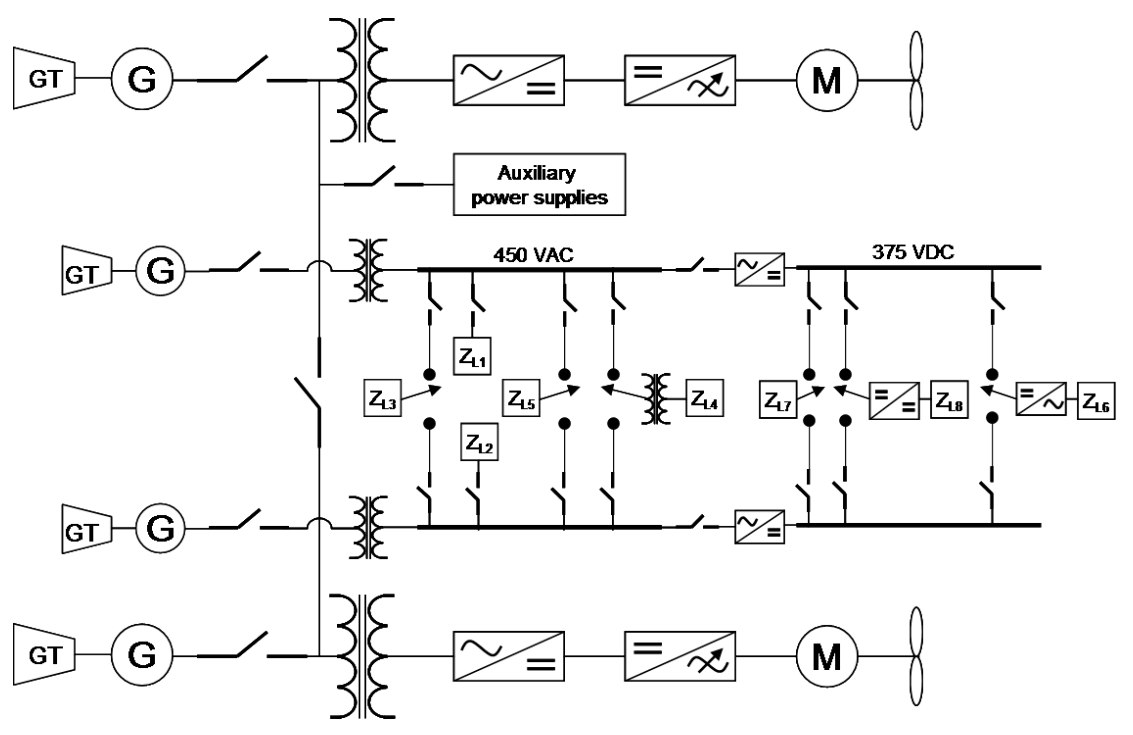

Fig. 1. Basic configuration of an electric ship power system.

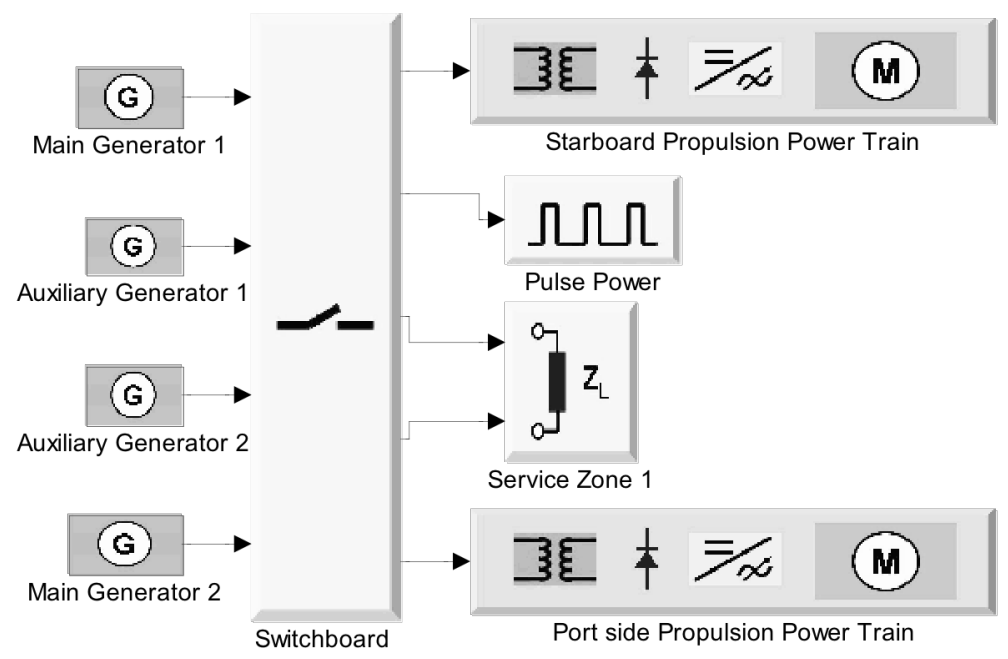

Fig. 2. Top-level Simulink model of the electric ship power system.

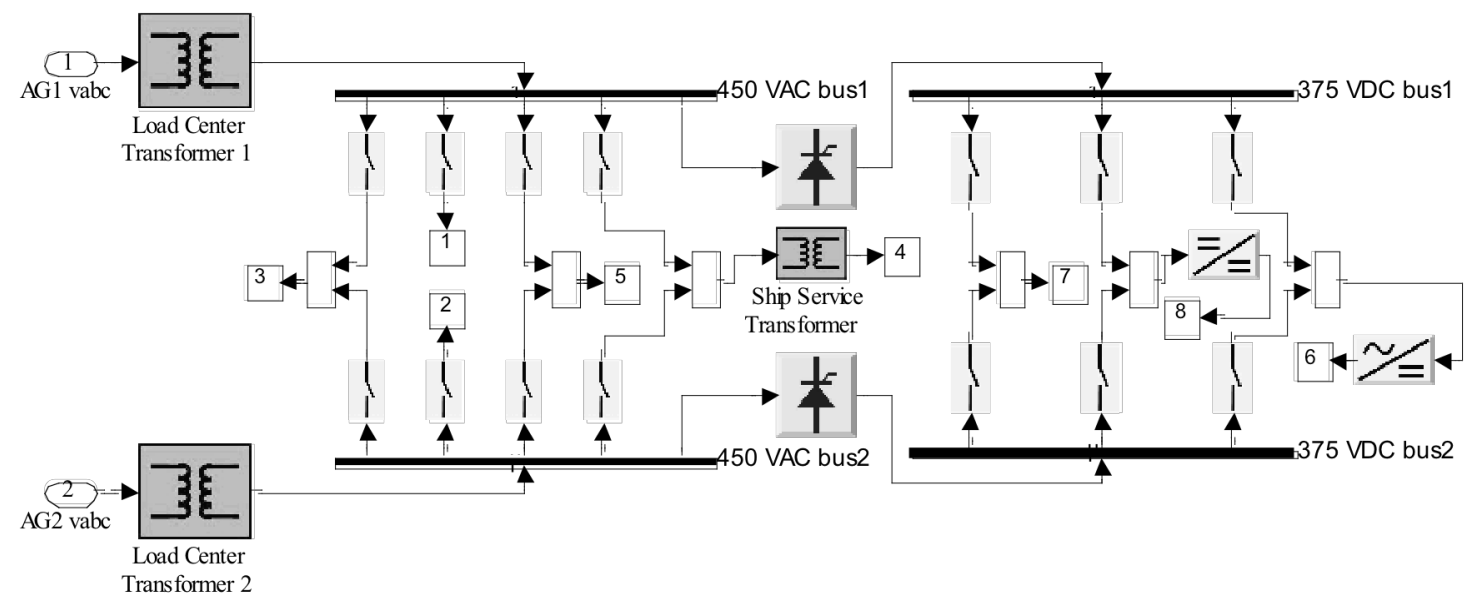

Fig. 3. Expanded model of ship service loads. 
The switchboard includes breakers, switches, and timers that allow the supply of power from any generator to any load. The present setting, as can be seen in Fig. 4. has only few breakers and switches that allow the transfer of power between the main generators to either propulsion power trains.

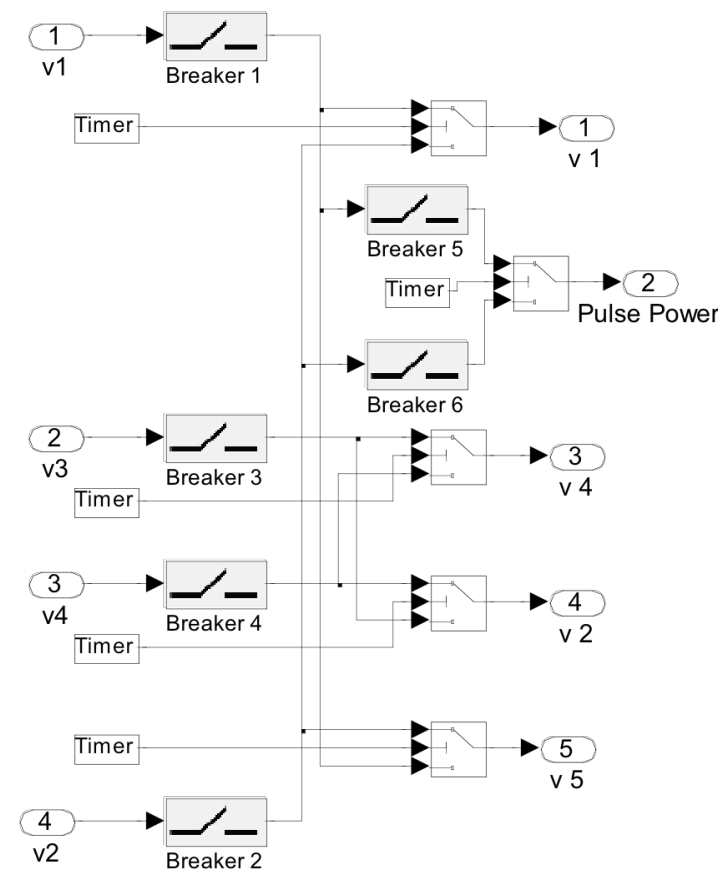

Fig. 4. Main switchboard with a simple breaker configuration.

The pulse power block represents a pulse power generator and load such as an EM gun system. This block was previously developed for an 800 MJ EM gun system using pre-programmed blocks as reported in [3]. We plan to rebuild a new model using only native Simulink blocks.

\section{ANALYSIS EXAMPLES}

Two examples showing the type of analyses that can be performed using the electric ship power system model are presented next. In the first example a loss of one of the main generators while supplying full power to the corresponding propulsion power train causes the breakers in the switchboard to reconfigure their open/close status to allow transfer of power from the working main generator to the propulsion power train that was originally supplied by the damaged generator. Since automatic fault sensing is not yet implemented in the model, the breakers are pre-programmed to change their status according to the scenario under study. Figure 5. shows the response of motor speed to the sudden loss of power followed by a transfer of power $10 \mathrm{~ms}$ later. Some transient effects appear in the affected propulsion motor while the speed of the second motor drops due to the transfer of power. The two propulsion motor speeds eventually stabilize at about $120 \mathrm{rpm}$ down from their top speed of 150 rpm while being equally supplied by a single generator. The drop of power by a factor of two while the speed drops only from $150 \mathrm{rpm}$ to $120 \mathrm{rpm}$ is due the cubic-law dependence of power on speed. Motor phase current response is shown in Fig. 6. An expanded view around the time the fault occurred is shown in Fig. 7.

This example is presented to illustrate the potential usefulness of this type of analyses to the naval architects and engineers who are working on ship designs and power system architectures.

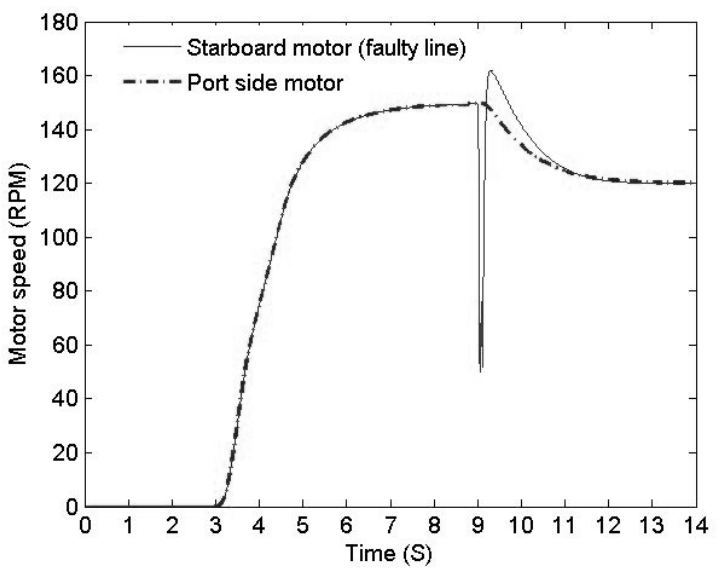

Fig. 5. Motor speed response.

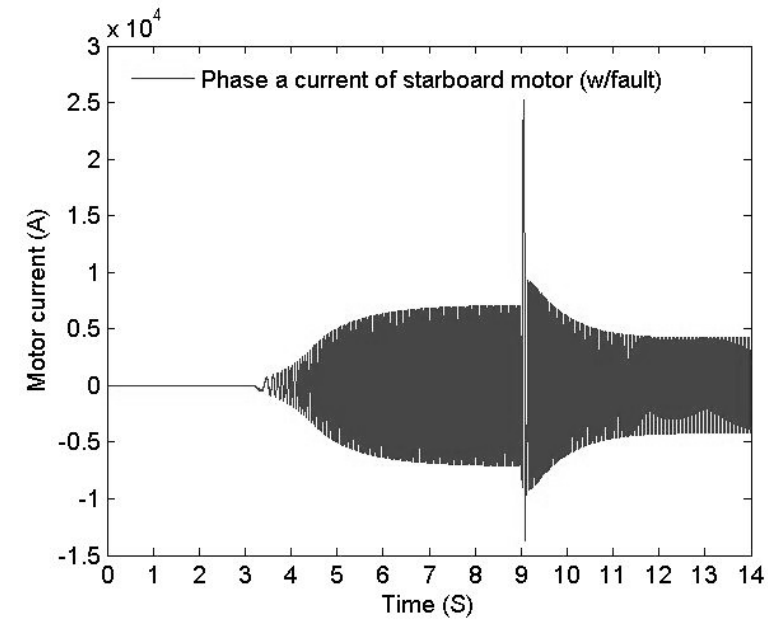

Fig. 6. Propulsion motor phase current.

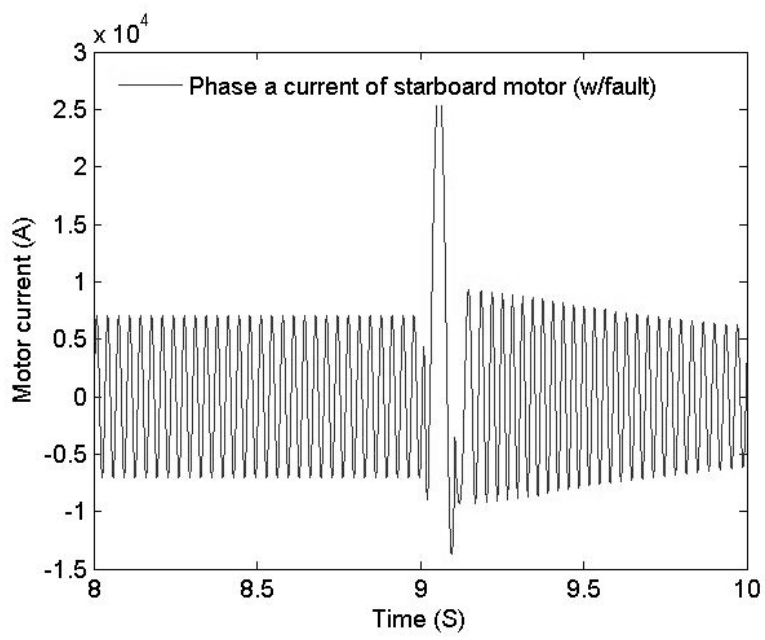

Fig. 7. Expanded view of propulsion motor phase current. 
In the second example power loss to a vital service load due to a fault on one of the 450 VAC distribution busses is simulated. Recovery of power to the vital load is achieved by shedding a non-vital load from the second bus prior to connecting the load. Breakers and switches are preprogrammed to follow a time sequence for changing their on/off status. As mentioned earlier automatic fault sensing will be implemented subsequently. As can be seen in Fig. 3. vital load 3 is connected to the upper $450 \mathrm{VAC}$ bus that becomes disabled due to an emergency. Before connecting the vital load to the working lower bus, non-vital load 2 is disconnected first. The transfer of power process is shown in Fig. 8. and the voltage across the vital load before and after the fault is shown in Fig. 9.

Finally, we would like to note that the arc suppression process is implemented in the breakers' model. In this process, after receiving the "open" instruction, the breaker will do so only after the current value becomes zero. Similarly, when it receives the "close" instruction it executes the command only when the voltage value is also zero. This process will affect the transient response.

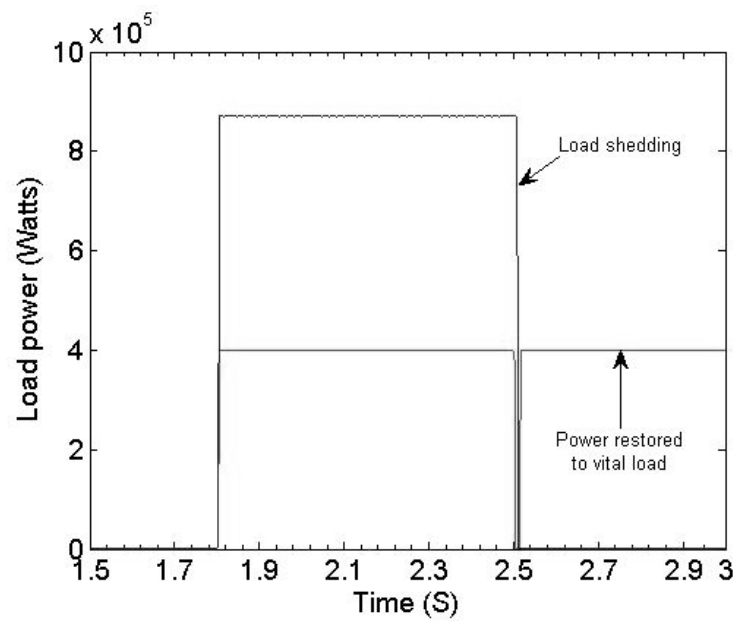

Fig. 8. Power loss and recovery to vital load.

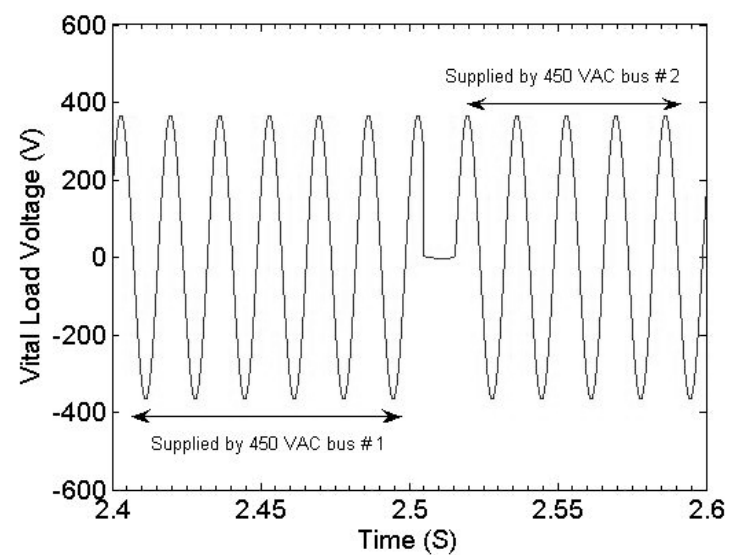

Fig. 9. Voltage across vital before and after fault.

\section{CONCLUSION}

An electric ship power system model was developed in the Matlab/Simulink computing environment. Analysis examples highlighting the usefulness of modeling and simulation approach to the design and analyses of the electric ship power system architecture were presented. A brief discussion on various computing environments was also presented.

As a concluding remark, it is important to note that the fidelity of the results of this type of analyses depends not only on the correctness of component models but on their parameters as well. For realistic transient analyses it is vital that these parameters be assigned actual values.

\section{REFERENCES}

[1] J. Beno, M. Flynn, R. Hayes, R. Hebner, J.R. Jackson, A. Ouroua, M. Pichot, E. Schroeder, J. Zierer, and D. Weeks, "Design and analysis of a 20 MW propulsion power train," presented at the $7^{\text {th }}$ Int. Conf. Naval Engineering Conference and Exhibition (INEC), Amsterdam, The Netherlands, 2004.

[2] E. Schroeder, M. Pichot, A. Ouroua, M. Flynn, and J. Beno, "Development of electric propulsion motors with integrated power electronics," presented at the Electric Machine Technology Symposium (EMTS), Philadelphia, PA, USA, 2004

[3] J. Beno, A. Ouroua, and M. Flynn, "Effect of EM weapons requirements on the electric ship power system," presented at the Engine as a Weapon Symposium, Bristol, UK, 2004.

[4] E.A. Lewis and J. Beno, "Managing multiple and varying energy demands by means of energy storage in combatants with integrated electric propulsion," presented at the Engine as a Weapon Symposium, Bristol, UK, 2004.

[5] R. Hebner, J. Pappas, J. Kitzmiller, K. Davey, J. Herbst, A. Ouroua, and J. Beno, "An electromagnetic gun power supply as a component of an electric ship power system," presented at the High Power Weapon Systems for Electric Ships Symposium, Annapolis, MD, USA, 2004.

[6] Syntek Technologies, Arlington, Virginia, USA.

[7] The AEgies Technology Group, Inc. 631 Discovery Drive, Huntsville, AL, 35806, USA.

[8] Virtual Test Bed, Department of Electrical Engineering, University of South Carolina, USA.

\section{BIOGRAPHIES}

A. Ouroua obtained his $\mathrm{PhD}$, MS, and BS degrees in physics from the University of Texas, the University of California at Los Angeles, and the University of Science and Technology of Algiers respectively. His present work concentration is on EM design and analysis of electric machines.

L. Domaschk holds a Bachelor of Science degree in electrical engineering from the University of Texas. Her work interest is in power systems and power electronics. Her present work focus is on modeling and simulation of the electric ship power system.

J. H. Beno has BS and MS degrees in engineering physics and a $\mathrm{PhD}$ in electrical engineering. He is an Associate Director at the University of Texas Center for Electromechanics where he leads programs in electric vehicles, electric ship technology, and advanced vehicular suspension systems. 